\title{
PENERAPAN METODE LINEAR PROGRAMMING DALAM PENENTUAN KOMBINASI POTONGAN PADA PEKERJAAN BEKISTING DI PROYEK $X$
}

\author{
Teosaner Yutanesy ${ }^{1}$ dan Iwan B. Santoso ${ }^{2}$ \\ ${ }^{1}$ Program Studi Sarjana Teknik Sipil, Universitas Tarumanagara, Jl. Letjen S. Parman No.1 Jakarta \\ Email: teosaner.325160119@stu.untar.ac.id \\ ${ }^{2}$ Program Studi Sarjana Teknik Sipil, Universitas Tarumanagara, Jl. Letjen S. Parman No.1 Jakarta \\ Email: iwsantoso@hotmail.com
}

Masuk: 15-01-2020, revisi: 10-02-2020, diterima untuk diterbitkan: 26-02-2020

\begin{abstract}
Conventional formwork using wood as the main material. Installation of wooden planks requires planned cuts to match the planned dimensions. One method that can be used to calculate the optimal result of selection of chunks is the linear programming method. First, determine the size of the combination of pieces that allow it to be done and according to the planned dimensions. Secondly, it modeled a single equation that optimizes the use of wooden planks after determining the size. Lastly, it outlines limiting equations to optimize wooden planks in the provision of materials for 3 floors and reuse 3 times. From modeling linear programming obtained for the provision of 3 floors material and reuse 3 times required wooden board as much as 2310.05 sheets, provision of 2 floors material and reuse 3 times required wooden board as much as 1925.04 sheets and provision of materials 2 floors and Reuse 4 times the required wooden board as much as 1540.03 sheets. The results of the comparison between the calculation of the area of work with linear programming modeling showed a decrease in the need for wood planks by $2.7 \%$.
\end{abstract}

Keywords: conventional formwork; linear programming; cut combinations; optimization; reuse

\section{ABSTRAK}

Pekerjaan bekisting konvensional menggunakan kayu sebagai material utama. Agar pemasangan dari papan kayu dapat dilakukan dengan baik diperlukan perencanaan pemotongan yang sesuai dengan dimensi yang direncanakan. Salah satu metode yang dapat digunakan untuk menghitung hasil optimal pemilihan potongan adalah metode linear programming. Pertama, menentukan ukuran dari kombinasi potongan yang memungkinan untuk dilakukan dan sesuai dengan dimensi yang direncanakan. Kedua, memodelkan satu persamaan yang mengoptimalisasi penggunaan papan kayu setelah menentukan ukuran tersebut. Terakhir, menguraikan persamaan-persamaan yang membatasi untuk mengoptimalisasi papan kayu dalam penyediaan material untuk 3 lantai dan reuse 3 kali. Dari pemodelan linear programming didapatkan untuk penyediaan material 3 lantai dan reuse 3 kali diperlukan papan kayu sebanyak 2310,05 lembar, penyediaan material 2 lantai dan reuse 3 kali diperlukan papan kayu sebanyak 1925,04 lembar dan penyediaan material 2 lantai dan reuse 4 kali diperlukan papan kayu sebanyak 1540,03 lembar. Hasil perbandingan antara perhitungan luas pekerjaan dengan pemodelan linear programming menunjukkan penurunan pembelian papan kayu sebanyak 2,7\%.

Kata kunci: bekisting konvensional; linear programming; kombinasi potongan; optimalisasi; reuse

\section{PENDAHULUAN}

Pada pekerjaan konstruksi terutama pekerjaan struktur beton bertulang, kayu sangat diperlukan. Kayu diperlukan sebagai bahan utama pembuatan bekisting. Bekisting ini akan membentuk elemen struktur kolom, balok, plat, dinding, dan lain-lain sesuai dengan dimensi dari yang direncanakan.

Isu pemanasan global telah banyak disebarluaskan oleh pemerintah dan komunitas pecinta alam sehingga menjadi isu utama yang menyebabkan penggunaan untuk keperluan industri dari sumber daya hutan semakin tertekan. Isu ini semakin luas yang menjadikan pemanfaatan hasil hutan yang didalamnya termasuk kayu akan semakin sulit untuk didapatkan. Oleh sebab itu, kayu yang merupakan material utama dari bekisting konvensional semakin sulit didapatkan dan penggunaan kayu hasil dari hutan sangat dibatasi jumlahnya.

Sejauh ini di Indonesia, material yang digunakan sebagai bekisting konvensional adalah kayu. Oleh sebab itu, sebagai salah satu langkah untuk mengurangi dan membatasi penggunaan kayu adalah dengan melakukan 
penghematan kayu. Penghematan dapat dilakukan dengan cara penentuan pemotongan dari satu papan kayu. Penentuan pemotongan satu papan kayu harus direncanakan dan sesuai dengan perencanaan tersebut.

Salah satu alternatif untuk melakukan penghematan dalam pemotongan kayu untuk bekisting adalah dengan metode Linear Programming. Linear programming adalah suatu teknis matematika yang dirancang untuk membantu dalam merencanakan dan membuat keputusan dalam sumber daya yang terbatas untuk mencapai suatu tujuan tertentu. Dengan demikian, penggunaan metode ini diharapkan dapat mengoptimalkan pemakaian dari kayu yang dipotong untuk penggunaan bekisting.

Tujuan dari penelitian ini adalah menganalisis hasil optimal kebutuhan papan kayu dari bekisting konvensional yang sesuai dengan gambar kerja, membuat panduan dalam melakukan proses pemotongan papan kayu yang dapat dijadikan bahan pengamatan dan pengawasan dan membuat pemodelan linear programming agar dapat mengkaji perencanaan, fabrikasi, dan reuse dari bekisting yang tepat sehingga didapatkan hasil optimal dari kebutuhan papan kayu.

Bekisting terdiri dari berbagai jenis dan metode pekerjaan sehingga terlalu luas untuk dibahas dalam penelitian ini. Oleh sebab itu, untuk penelitian ini lebih terarah maka penulis menenetapkan beberapa batasan di antaranya adalah permasalahan mengenai bekisting yang digunakan terbatas pada bekisting konvensional, permasalahan mengenai perencanaan, fabrikasi dan reuse bekisting yang digunakan pada pekerjaan struktur atas (balok dan pelat lantai), usaha penghematan dari bekisting yang diteliti terbatas pada perencanaan bekisting, fabrikasi bekisting, dan reuse dari bekisting, pemodelan yang digunakan dalam penelitian ini adalah linear programming, perencanaan bekisting terbatas pada keperluan potongan kayu di setiap zona yang dihitung, ukuran papan kayu yang digunakan $122 \mathrm{x}$ $244 \mathrm{~cm}$, pemodelan tidak memperhitungkan penjadwalan dari kebutuhan waktu pemasangan, pengecoran dan pembongkaran, papan kayu yang digunakan dalam penelitian ini memiliki ketebalan $12 \mathrm{~mm}$ dan dapat digunakan kembali 3-5 kali, denah setiap lantai Proyek X merupakan lantai tipikal, pemodelan mengabaikan kehilangan bahan akibat pemotongan, pemasangan papan dipasang sesuai arah panjang.

\section{Bekisting}

Menurut Wigbout (1992), bekisting memiliki 3 fungsi yaitu:

- Bekisting menentukan bentuk dari konstruksi beton yang akan dibuat. Bentuk sederhana dari sebuah konstruksi beton menghendaki sebuah bekisting yang sederhana.

- Bekisting harus dapat menyerap dengan aman beban yang ditimbulkan oleh spesi beton dan berbagai beban luar serta getaran. Dalam hal ini perubahan bentuk yang timbul dan geseran-geseran dapat diperkenankan asalkan tidak melampaui toleransi-toleransi tertentu.

- Bekisting harus dapat dengan cara sederhana dipasang, dilepas, dan dipindahkan.

Sistem konvensional masih merupakan sistem bekisting yang paling umum dan populer. Popularitas sistem konvensional berasal dari kemampuan untuk membentuk berbagai bentuk dan dimensi. Namun, sistem konvensional biasanya menghasilkan biaya tenaga kerja dan material yang tinggi. Sistem non konvensional mendapatkan popularitas yang semakin meningkat karena biaya tenaga kerja yang rendah dan kemampuan mereka untuk mengerjakan konstruksi dengan lebih cepat.

\section{Kayu bekisting}

Kayu sangat banyak digunakan di dalam bidang konstruksi terutama di dalam pekerjaan bekisting. Kayu ini diambil dari pohon dan diklasifikasi menjadi 2 bagian yaitu hardwood dan softwood. Hardwood berasal dari pohon yang memiliki daun lebar. Softwood berasal dari pohon yang memiliki daun yang seperti jarum. Softwood lebih umum digunakan untuk konstruksi bekisting. Pengertian hardwood dan softwood tidak mengindikasikan pada kekerasan dari kayu tersebut (Hanna, 1999).

Menurut Wigbout (1992), kayu memiliki sifat-sifat yang menguntungkan yaitu:

- Kekuatan yang besar pada suatu massa volumik yang kecil

- Harga yang relatif rendah dan dapat diperoleh dengan mudah

- Mudah dikerjakan dan alat-alat sambung yang sederhana

- Isolasi termis yang sangat baik

- Dapat dengan baik menerima tumbukan-tumbukan dan getaran-getaran serta penanganan yang kasar di tempat pendirian sebuah bangunan.

Akan tetapi, kayu juga memiliki sifat-sifat yang tidak menguntungkan yaitu: 
- Anisotrop, memiliki sifat yang tidak sama dalam semua arah

- Tidak homogen, serat-seratnya tidak terbagi rata pada kayu

- Menyusut dan mengembangnya kayu tergantung dari pergantian cuaca

- Tahanan terhadap retakan dan geseran kecil sekali

- Keterbatasan dalam ukuran-ukuran

- Kemungkinan penggunaan ulang yang terbatas

- Kekuatannya akan berkurang, sejalan dengan lebih membasahnya keadaan. Suatu kadar basahan $21 \%$ dan lebih tinggi dari ini dapat menimbulkan busukan kayu.

\section{Bekisting tradisional}

Bekisting tradisional adalah kayu papan dan kayu balok dikerjakan di tempat oleh orang-orang ahli. Dalam bentuk yang rumit harus banyak diadakan penggergajian sehingga penggunaannya hanya terbatas sampai pada hanya beberapa kali penggunaannya. Dengan demikian bekisting tradisional memerlukan banyak pengerjaan dan upah. Biaya investasinya dapat dikatakan rendah karena hilangan-hilangan yang cukup tinggi oleh penggergajian dan buangan. Papan-papan dapat diganti oleh panel-panel yang dibuat pabrik. Panel-panel ini, asalkan saja digunakan secara benar, dapat memberikan suatu kemungkinan pengulangan yang lebih tinggi sehingga dapat menghemat tenaga kerja.

\section{Fabrikasi bekisting}

Langkah kedua dari daur hidup bekisting adalah fabrikasi bekisting. Aktivitas ini didalamnya termasuk menerima material bekisting, memotong dan mengumpulkan material sesuai dengan ukuran dan tipe, mengelompokkan potongan tersebut ke dalam bentuk dan ukuran yang diinginkan, dan menyimpan kelompok-kelompok tersebut ke alat pengangkutan barang. Kontraktor dapat memilih disekitar proyek untuk tempat khusus fabrikasi atau membuat banyak tempat fabrikasi di antara proyek dan dengan alat pengangkutan barang, mengangkut barang tersebut ke lokasi yang dituju (Hanna, 1999).

Penggergajian kayu untuk bekisting menurut Kusuma, Kole, dan Sagel (1993) harus dilakukan seefisien mungkin supaya papan bekisting yang lebar dan balok-balok yang panjang dapat dipakai berulang-ulang. Apabila dikerjakan dengan seksama, maka papan dapat digunakan 3-4 kali, sedangkan untuk balok persegi dan bulat dapat dipakai 7-10 kali.

\section{Reuse bekisting}

Reuse bekisting untuk pekerjaan beton bertulang adalah kunci untuk konstruksi bekisting yang ekonomis. Setelah reuse sampai lima kali, biaya material bekisting turun menjadi 40 persen dari biaya awal.

Elemen bekisting harus ditangani dengan hati-hati dan tidak boleh dijatuhkan. Setelah memperbaiki, membersihkan, dan meminyaki, elemen bekisting yang digunakan ditimbun di daerah pekerjaan konstruksi selanjutnya. Sebelum menggunakan kembali elemen bekisting, diperiksa terlebih dahulu untuk kerusakannya. Cacat atau kerusakan pada bagian yang berkenaan dengan permukaan beton perlu diperbaiki atau dilepas karena akan mempengaruhi permukaan beton yang terbentuk (Hanna, 1999).

\section{LINEAR PROGRAMMING}

Linear programming berkaitan dengan masalah meminimalkan atau memaksimalkan fungsi linear dengan adanya persamaan linear. Sejak pengembangan metode simpleks oleh George B. Dantzig pada tahun 1947, linear programming telah banyak digunakan dalam bidang militer, industri, pemerintahan, perencanaan kota, dan lainlain. Popularitas pemakaian linear programming dikarenakan mampu memodelkan masalah besar dan kompleks. Selain itu, mampu memecahkan masalah tersebut dengan waktu yang cepat karena menggunakan algoritma yang efektif dan komputer (Bazaraa dkk; 2010).

Masalah mendasar dalam optimasi adalah untuk sampai pada keputusan terbaik di bawah beberapa keadaan tertentu yang berkatian dengan masalah optimasi, yang diambil dalam kemungkinan-kemungkinan kejadian yang dapat menentukan keputusan yang diambil. Dalam masalah linear programming, kita harus mengoptimalkan sejumlah fungsi dibawah kendala-kendala yang ada (Islam, 2008).

Linear programming adalah alat untuk memecahkan suatu masalah optimasi suatu model linear dengan keterbatasan-keterbatasan sumber daya yang tersedia. Secara umum, fungsi pada model ini ada dua macam yaitu 
fungsi tujuan dan fungsi pembatas. Fungsi tujuan dimaksudkan untuk menentukan nilai optimum dari fungsi tersebut yaitu memaksimalkan masalah keuntungan dan meminimalkan masalah biaya. Fungsi pembatas dimaksudkan untuk keperluan yang berkenaan dengan pembatasan sumber daya yang tersedia, misalnya jumlah bahan baku, waktu kerja, jumlah tenaga kerja, dan luas gudang persediaan. Tujuan utama dari linear programming adalah menentukan nilai optimum dari fungsi tujuan yang telah ditetapkan.

Lindo (Linear, INteractive, and Discrete Optimizer) adalah software yang dapat digunakan untuk mencari penyelesaian dari masalah linear programming. Software ini memungkinkan perhitungan masalah linear programming dengan 300 variabel. Prinsip kerja utama Lindo adalah memasukkan data, menyelesaikan, serta menaksirkan kebenaran dan kelayakan data berdasarkan penyelesaiannya.

Untuk menentukan nilai optimal dengan menggunakan Lindo diperlukan beberapa tahapan yaitu:

1. Menentukan model matematika berdasarkan data real.

2. Menentukan formulasi program untuk Lindo.

3. Membaca hasil report yang dihasilkan oleh Lindo.

\section{HASIL DAN PEMBAHASAN}

\section{Pengelompokkan data}

Pembuatan model sangat ditentukan dengan olahan data yang dikerjakan terlebih dahulu. Oleh sebab itu, diperlukan olahan data yang lengkap dan terperinci. Data yang sudah diperoleh adalah denah tipikal proyek yang memiliki 30 lantai.

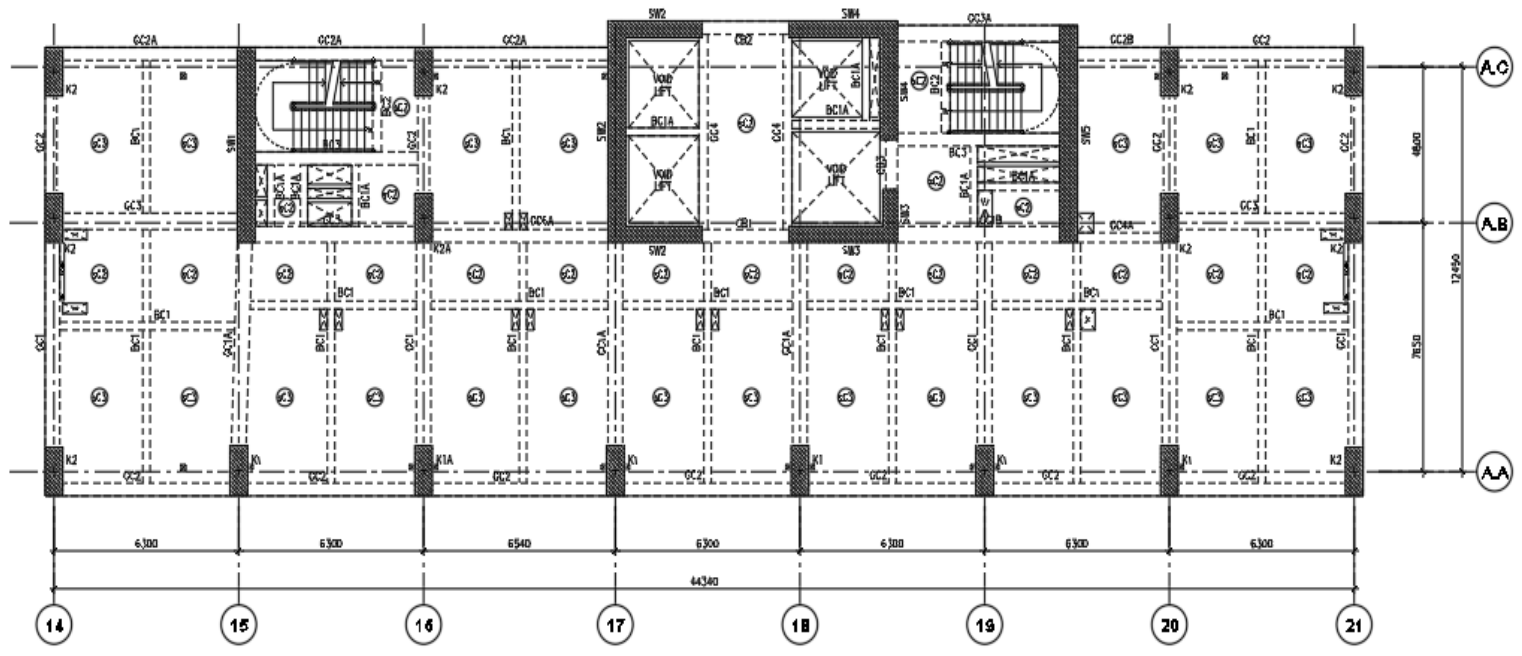

Gambar 1. Denah tipikal proyek

Perincian dimensi dari kolom dan balok menunjukkan bahwa dimensi dari balok adalah beragam. Oleh sebab itu, diperlukan pengelompokkan data agar dalam pengolahan data lebih mudah. Pengelompokkan data dimulai dari mengelompokkan balok yang memiliki lebar dengan ukuran yang sama dan dilanjutkan dengan pengelompokkan balok yang memiliki tinggi dengan ukuran yang sama. Pengelompokkan lebih baik ditandai dengan mewarnai balok yang ingin dihitung pada denah sehingga dalam mengolah data menjadi jelas dan terperinci. Pengelompokkan balok dengan lebar $250 \mathrm{~mm}, 300 \mathrm{~mm}, 400 \mathrm{~mm}$, dan $500 \mathrm{~mm}$. Pengelompokkan balok dengan tinggi $500 \mathrm{~mm}$ dan $600 \mathrm{~mm}$. Contoh perincian balok dapat dilihat pada tabel 1 sedangkan contoh pengelompokkan balok dapat dilihat pada gambar 2 .

Tabel 1. Contoh dimensi balok

\begin{tabular}{ll}
\hline Balok & Dimensi $(\mathrm{mm})$ \\
\hline GC1 & $500 \times 600$ \\
\hline GC2 & $400 \times 500$
\end{tabular}




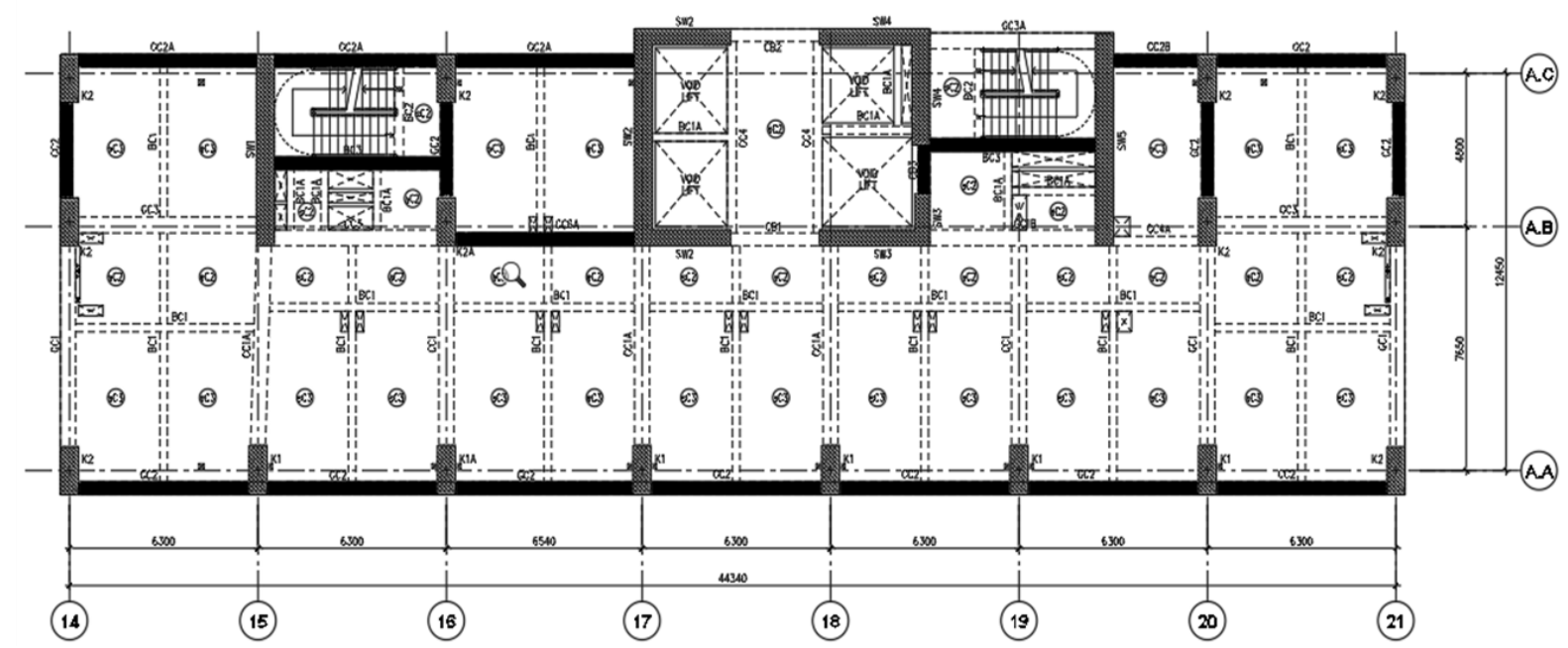

Gambar 2. Pengelompokkan balok dengan lebar $400 \mathrm{~mm}$

Pengelompokkan data dilanjutkan dengan mengelompokkan tipe pelat yang memiliki dimensi yang sama. Diketahui tebal semua pelat yaitu $150 \mathrm{~mm}$. Pengelompokkan data berasal dari panjang dan lebar pelat yang sama. Contoh pengelompokkan tipe pelat dapat dilihat pada tabel 2.

Tabel 2. Contoh pengelompokkan pelat

\begin{tabular}{ccc}
\hline Tipe Pelat & Panjang $(\mathrm{m})$ & Lebar $(\mathrm{m})$ \\
\hline 1 & 4.7 & 2.83 \\
\hline 2 & 2.85 & 2.83 \\
\hline 3 & 4.7 & 2.93 \\
\hline
\end{tabular}

\section{Pengolahan data}

Data-data yang sudah dikelompokkan diolah sesuai dengan keperluan pembuatan model. Dalam model yang dibuat memerlukan panjang dan volume pekerjaan dari dimensi yang sudah dikelompokkan. Data yang didapatkan terlebih dahulu dibagi dalam zona yang sudah ditentukan. Denah dibagi menjadi 2 zona. Pembagian zona bisa dilihat pada gambar 3. Zona 1 adalah bagian yang diarsir dan zona 2 bagian yang tidak diarsir.

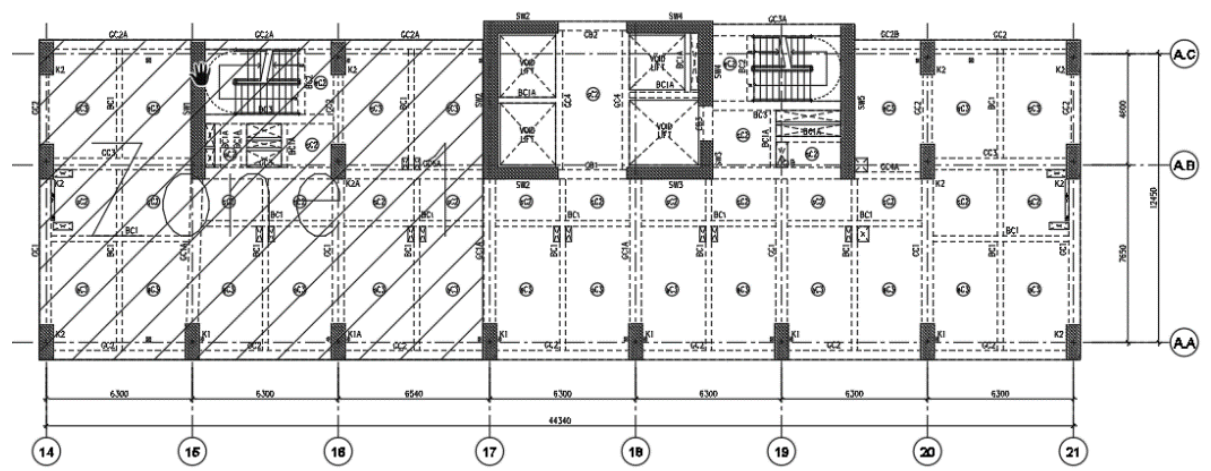

Gambar 3. Pembagian Zona

Pembagian zona ini berpengaruh pada panjang dan volume pekerjaan yang sudah dikelompokkan terdahulu. Oleh sebab itu, dalam pengolahan data memperhatikan pembagian zona tersebut. Dalam pengolahan data keperluan panjang dari pekerjaan balok, perlu mengetahui panjang dari as-as dan dimensi kolom. Panjang balok adalah 
bentang bersih dari as-as dikurangkan dimensi kolom. Dengan demikian, dapat diperoleh perhitungan keperluan panjang dari masing-masing balok dengan lebar yang sama. Hasil perhitungan keperluan panjang balok dari masing-masing lebar dan tinggi dimasing-masing zona dilihat pada tabel 3.

Tabel 3. Hasil perhitungan keperluan panjang ba
\begin{tabular}{cc}
\multicolumn{2}{c}{ Zona 1} \\
\hline Lebar (cm) & Panjang (cm) \\
\hline 50 & 3015 \\
\hline 40 & 5256 \\
\hline
\end{tabular}

Pada pekerjaan pelat, keperluan panjang dapat dihitung dari kombinasi lebar yang memungkinkan untuk bekisting dapat dipasang dari lebar pelat tersebut. Rincian lebar pelat dan kombinasi lebar bekisting yang diperlukan dapat dilihat pada tabel 4 .

Tabel 4. Contoh rincian lebar pelat dan kombinasi lebar bekisting

\begin{tabular}{cccc}
\hline Pelat & Lebar $(\mathrm{m})$ & Lebar $(\mathrm{cm})$ & Kombinasi $(\mathrm{cm})$ \\
\hline 1 & 2.83 & 283 & $2 \times 122+37+2$ \\
\hline 2 & 2.83 & 283 & $2 \times 122+37+2$ \\
\hline 3 & 2.93 & 293 & $2 \times 122+49$ \\
\hline 4 & 3.03 & 303 & $122+47+2 \times 25+46+38$ \\
\hline 5 & 2.78 & 278 & $122+3 \times 40+36$ \\
\hline 6 & 2.78 & 278 & $122+3 \times 40+36$ \\
\hline 7 & 2.78 & 278 & $122+3 \times 40+36$ \\
\hline 8 & 2.78 & 278 & $122+3 \times 40+36$ \\
\hline
\end{tabular}

Perhitungan volume dari pekerjaan bekisting adalah berdasarkan luas permukaan. Oleh sebab itu, perhitungan luas permukaan dari pekerjaan balok maupun pekerjaan pelat dapat dihitung dengan perkalian antara lebar dan panjang masing-masing lapisan permukaan. Luas permukaan total yang didapatkan masing-masing perkerjaan dapat dibagi dengan luas 1 kayu kayu bekisting. Dimensi kayu bekisting adalah 122 x $244 \mathrm{~cm}$. Hasil pembagian tersebut mendapatkan jumlah papan kayu bekisting yang digunakan. Total luas pekerjaan bekisting dalam perhitungan 1 lantai pada zona 1 adalah $3036652,9 \mathrm{~cm}^{2}$ dan pada zona 2 adalah $3715614,5 \mathrm{~cm}^{2}$. Total papan kayu yang digunakan dalam zona 1 adalah 103 papan dan zona 2 adalah 126 papan dalam perhitungan 1 lantai.

\section{Pemodelan linear progamming}

Pemodelan optimasi pemakaian kayu bekisting dalam pekerjaan pelat dan balok sebagai berikut: 


\section{A. Decision variables}

Decision variable dalam pemodelan ini adalah kombinasi potongan dalam 1 papan kayu bekisting yang disesuaikan dengan keadaan lapangan. Penelitian ini menggunakan 16 variabel untuk 1 zona. Total variable yang digunakan adalah 32 variabel. IA adalah kombinasi potongan 1 di zona 1 dan IB adalah kombinasi potongan 1 di zona 2. Contoh kombinasi potongan yang dibentuk dalam penelitian ini dapat dilihat pada gambar 4 .

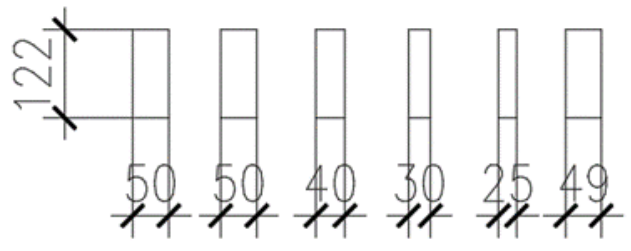

Gambar 4. Contoh kombinasi potongan yang dibentuk

\section{B. Objective function}

Objective Function dari penelitian ini adalah untuk mendapatkan jumlah kayu bekisting yang optimal dengan mempertimbangkan keperluan panjang dari dimensi balok dan jumlah papan kayu pekerjaan balok dan pelat yang didapatkan dari luas pekerjaan.

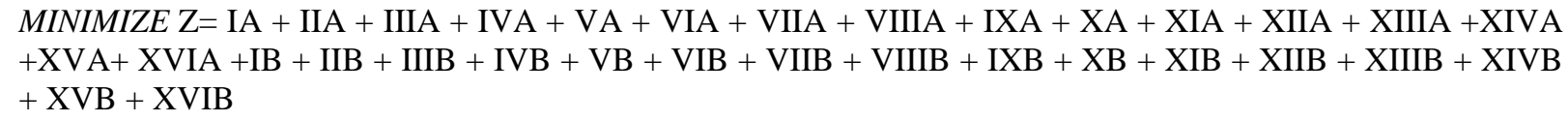

\section{Constraints}

Penyediaan material bekisting sebanyak 3 lantai dan reuse selama 3 kali dengan volume pekerjaan sebanyak 30 lantai tipikal. Penyediaan material sebanyak 3 lantai dan reuse 3 kali sama dengan kebutuhan material untuk 12 lantai. Constraint yang dibutuhkan agar dapat mendapatkan hasil optimal adalah sebagai berikut:

- $\quad$ Terhadap keperluan panjang di zona 1.

$>$ Berdasarkan keperluan panjang potongan $50 \mathrm{~cm}$ di zona 1 $366 \mathrm{IIA}+244 \mathrm{IIIA}+122 \mathrm{IVA}+244 \mathrm{VA}+366 \mathrm{VIA}+244 \mathrm{IXA}+122 \mathrm{XVIA}>=80640$

$>$ Berdasarkan keperluan panjang potongan $40 \mathrm{~cm}$ di zona 1 122IIIA+122IVA+244VIIA+732VIIIA+122IXA+366XVIA >=173124

$>$ Berdasarkan keperluan panjang potongan $30 \mathrm{~cm}$ di zona 1 122IIIA+244IVA+976XA > $=20460$

$>$ Berdasarkan keperluan panjang potongan $25 \mathrm{~cm}$ di zona 1 244VA+488XIA+732XIIA $>=78288$

$>$ Berdasarkan keperluan panjang potongan $122 \mathrm{~cm}$ di zona 1 244IA $>=99408$

$>$ Berdasarkan keperluan panjang potongan $46 \mathrm{~cm}$ di zona 1 244VIIA+244XVA $>=5640$

$>$ Berdasarkan keperluan panjang potongan $49 \mathrm{~cm}$ di zona 1 122IIIA+244XIVA $>=7908$

$>$ Berdasarkan keperluan panjang potongan $37 \mathrm{~cm}$ di zona 1 488XIIIA+244XVIA $>=15300$

$>$ Berdasarkan keperluan panjang potongan $36 \mathrm{~cm}$ di zona 1 244VIIA+488XIA>=38184

$>$ Berdasarkan keperluan panjang potongan $47 \mathrm{~cm}$ di zona 1 244IVA+244VA+244VIA+122IXA+244XIIA $>=5640$

$>$ Berdasarkan keperluan panjang potongan $48 \mathrm{~cm}$ di zona 1 244 XIIIA +244XIVA $>=5652$

$>$ Berdasarkan keperluan panjang potongan $2 \mathrm{~cm}$ di zona 1 244VIIIA+244XA > $=15300$

$>$ Berdasarkan keperluan panjang potongan $38 \mathrm{~cm}$ di zona 1 122IIA+488XVA $>=5640$

- Terhadap keperluan panjang dari sisi vertikal balok di zona 1.

$>$ Berdasarkan keperluan panjang potongan $36-40 \mathrm{~cm}$ di zona 1 122IIA+122IIIA+122IVA+244VIIA+732VIIIA+122IXA+488XIA+488XIIIA 
+488 XVA+610XVIA $>=372204$

$>$ Berdasarkan keperluan panjang potongan $46-50 \mathrm{~cm}$ di zona 1

366IIA+366IIIA+366IVA+488VA+610VIA+244VIIA+366IXA+244XIIA+244XIIIA +488 XIVA+244XVA+122XVIA > $=142668$

- $\quad$ Terhadap jumlah papan kayu bekisting sesuai dengan perhitungan luas permukaan di zona 1 .

$>$ Berdasarkan jumlah papan kayu bekisting sesuai dengan perhitungan luas permukaan di zona 1 $\mathrm{IA}+\mathrm{IIA}+\mathrm{IIIA}+\mathrm{IVA}+\mathrm{VA}+\mathrm{VIA}+\mathrm{VIIA}+\mathrm{VIIIA}+\mathrm{IXA}+\mathrm{XA}+\mathrm{XIA}+\mathrm{XIIA}+\mathrm{XIIIA}+\mathrm{XIVA}$ $+\mathrm{XVA}+\mathrm{XVIA}<=1236$

- $\quad$ Terhadap keperluan panjang di zona 2.

$>$ Berdasarkan keperluan panjang potongan $50 \mathrm{~cm}$ di zona 2 $366 \mathrm{IIB}+244 \mathrm{IIIB}+122 \mathrm{IVB}+244 \mathrm{VB}+366 \mathrm{VIB}+244 \mathrm{IXB}+122 \mathrm{XVIB}>=71592$

$>$ Berdasarkan keperluan panjang potongan $40 \mathrm{~cm}$ di zona 2 122IIIB+122IVB+244VIIB +732VIIIB+122IXB+366XVIB > $=261384$

$>$ Berdasarkan keperluan panjang potongan $30 \mathrm{~cm}$ di zona 2 $122 \mathrm{IIIB}+244 \mathrm{IVB}+976 \mathrm{XB}>=32412$

$>$ Berdasarkan keperluan panjang potongan $25 \mathrm{~cm}$ di zona 2 $244 \mathrm{VB}+488 \mathrm{XIB}+732 \mathrm{XIIB}>=95436$

$>$ Berdasarkan keperluan panjang potongan $122 \mathrm{~cm}$ di zona 2 244IB $>=112680$

$>$ Berdasarkan keperluan panjang potongan $46 \mathrm{~cm}$ di zona 2 244 VIIB+244XVB $>=7200$

$>$ Berdasarkan keperluan panjang potongan $49 \mathrm{~cm}$ di zona 2 $122 \mathrm{IIIB}+244 \mathrm{XIVB}>=9024$

$>$ Berdasarkan keperluan panjang potongan $37 \mathrm{~cm}$ di zona 2 488XIIIB+244XVIB $>=21060$

$>$ Berdasarkan keperluan panjang potongan $36 \mathrm{~cm}$ di zona 2 244VIIB+488XIB > $=60540$

$>$ Berdasarkan keperluan panjang potongan $47 \mathrm{~cm}$ di zona 2 244IVB+244VB+244VIB+122IXB +244XIIB $>=2952$

$>$ Berdasarkan keperluan panjang potongan $2 \mathrm{~cm}$ di zona 2 244 VIIIB $+244 \mathrm{XB}>=14700$

$>$ Berdasarkan keperluan panjang potongan $38 \mathrm{~cm}$ di zona 2 $122 \mathrm{IIB}+488 \mathrm{XVB}>=1308$

- $\quad$ Terhadap keperluan panjang dari sisi vertikal balok di zona 2.

$>$ Berdasarkan keperluan panjang potongan $36-40 \mathrm{~cm}$ di zona 2 $122 \mathrm{IIB}+122 \mathrm{IIIB}+122 \mathrm{IVB}+244 \mathrm{VIIB}+732 \mathrm{VIIIB}+122 \mathrm{IXB}+488 \mathrm{XIB}+488 \mathrm{XIIIB}$ $+488 X V B+610 X V I B>=517692$

$>$ Berdasarkan keperluan panjang potongan $46-50 \mathrm{~cm}$ di zona 2 366IIB+366IIIB+366IVB+488VB+610VIB+244VIIB+366IXB+244XIIB+244XIIIB $+488 \mathrm{XIVB}+244 \mathrm{XVB}+122 \mathrm{XVIB}>=127404$

- $\quad$ Terhadap jumlah papan kayu bekisting sesuai dengan perhitungan luas permukaan di zona 2.

$>$ Berdasarkan jumlah papan kayu bekisting sesuai dengan perhitungan luas permukaan di zona 2 $\mathrm{IB}+\mathrm{IIB}+\mathrm{IIIB}+\mathrm{IVB}+\mathrm{VB}+\mathrm{VIB}+\mathrm{VIIB}+\mathrm{VIIIB}+\mathrm{IXB}+\mathrm{XB}+\mathrm{XIB}+\mathrm{XIIB}+\mathrm{XIIIB}+\mathrm{XIVB}$ $+\mathrm{XVB}+\mathrm{XVIB}<=1512$

- Non-negativity.

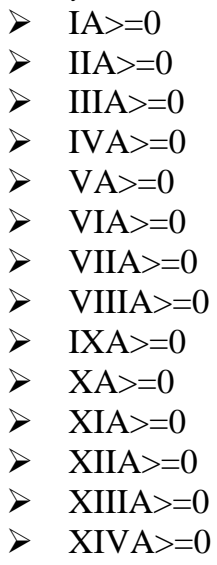




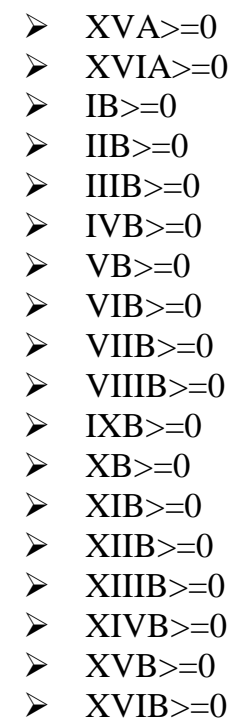

Berdasarkan hasil pengolahan data menggunakan Lindo, maka didapatkan hasil optimal jumlah penggunaan kayu bekisting pada proyek $\mathrm{x}$.

\section{Hasil}

Hasil optimal yang sudah didapatkan dengan menggunakan program Lindo, di bentuk dalam tabel dengan perincian potongan kombinasi dan zona agar lebih mudah dimengerti. Hasil optimal papan kayu bekisting untuk penyediaan 3 lantai dan reuse 3 kali dapat dilihat dalam tabel 5.

Tabel 5. Hasil dengan penyediaan 3 lantai dan reuse 3 kali

\begin{tabular}{|c|c|c|}
\hline Kombinasi & Zona & Hasil \\
\hline $1(122 \times 244)$ & \multirow{14}{*}{1} & 407.409851 \\
\hline $2(50,50,50,56,38 \times 122)$ & & 0 \\
\hline $3(50,50,40,30,25,49 \times 122)$ & & 18.491804 \\
\hline $4(50,40,30,30,47,47 \times 122)$ & & 43.153229 \\
\hline $5(50,25,47 \times 244)$ & & 0 \\
\hline $6(50,50,50,47,47 \times 122)$ & & 79.353966 \\
\hline $7(40,36,46 \times 244)$ & & 0 \\
\hline $8(40,40,40,2 \times 244)$ & & 54.841587 \\
\hline $9(50,50,40,57,47 \times 122)$ & & 0 \\
\hline $10(30,30,30,30,2 \times 244)$ & & 7.863332 \\
\hline $11(25,25,36,36 \times 244)$ & & 160.426224 \\
\hline $12(25,25,25,47 \times 244)$ & & 0 \\
\hline $13(37,37,48 \times 244)$ & & 0 \\
\hline $14(25,48,49 \times 244)$ & & 23.163935 \\
\hline
\end{tabular}




\begin{tabular}{cc}
\hline $15(38,38,46 \times 244)$ & 76.132149 \\
$16(50,40,40,40,37,37 \times 122)$ &
\end{tabular}

\section{KESIMPULAN DAN SARAN}

\section{Kesimpulan}

Kesimpulan yang didapatkan dari penelitian ini adalah

1. Hasil penelitian dengan menggunakan keperluan panjang zona 1 dan zona 2 dan jumlah kayu bekisting dengan menghitung kebutuhan luas permukaan, dengan penyediaan 3 lantai dan reuse sebanyak 3 kali menunjukkan bahwa untuk melakukan pekerjaan balok dan pekerjaan pelat sebanyak 30 lantai membutuhkan 2674,02 papan kayu.

2. Hasil penelitian dengan keadaan penyediaan 2 lantai dan reuse sebanyak 3 kali menunjukkan bahwa untuk melakukan pekerjaan balok dan pekerjaan pelat sebanyak 30 lantai membutuhkan 2228,35 papan kayu.

3. Hasil penelitian dengan keadaan penyediaan 2 lantai dan skenario reuse sebanyak 4 kali menunjukkan bahwa untuk melakukan pekerjaan balok dan pekerjaan pelat sebanyak 30 lantai membutuhkan 1782,68 papan kayu.

4. Hasil penelitian dengan keadaan penyediaan 2 lantai dan skenario reuse sebanyak 5 kali menunjukkan bahwa untuk melakukan pekerjaan balok dan pekerjaan pelat sebanyak 30 lantai membutuhkan 1335,01 papan kayu.

5. Hasil perbandingan antara keadaan penyediaan 3 lantai dan reuse sebanyak 3 kali dengan keadaan penyediaan 2 lantai dan reuse sebanyak 3 kali menunjukkan penurunan pembelian papan kayu sebanyak $16,667 \%$.

6. Hasil perbandingan antara keadaan penyediaan 2 lantai dan reuse sebanyak 3 kali dengan keadaan penyediaan 2 lantai dan reuse sebanyak 4 kali menunjukkan penurunan pembelian papan kayu sebanyak 20 $\%$.

7. Hasil perbandingan antara keadaan penyediaan 2 lantai dan reuse sebanyak 4 kali dengan keadaan penyediaan 2 lantai dan reuse sebanyak 5 kali menunjukkan penurunan pembelian papan kayu sebanyak $33,333 \%$.

8. Hasil perbandingan antara perhitungan luas pekerjaan dengan pemodelan linear programming menunjukkan penurunan pembelian papan kayu sebanyak $2,7 \%$.

\section{Saran}

Dalam penelitian ini digunakan lantai yang tipikal, diharapkan pada penelitian lebih lanjut dapat diteliti dengan menggunakan lantai yang tidak tipikal dan memperhatikan faktor-faktor yang lain yang berpengaruh terhadap pemilihan skenario penyediaan kayu bekisting pada pekerjaan balok dan pelat.

\section{DAFTAR PUSTAKA}

Astanto, Triono Budi. Konstruksi Beton Bertulang. Yogyakarta: Kanisius. 2001.

Bazaraa, Mokhtar S., John J. Jarvis, dan Hanif D. Sherali. Linear Programming and Network Flows. $4^{\text {th }}$ Edition. Hoboken: John Wiley \& Sons, Inc. 2010.

Hanna, Awad S. Concrete Formwork Systems. New York: Marcel Dekker, Inc. 1999.

Islam, S. M. Shahidul. Linear Programming. Dhaka: Bangla Muddranalay. 2008.

Kusuma, G., Kole P., dan Sagel R. Pedoman Pengerjaan Beton Berdasarkan SK SNI T -15-1991- 03 Seri 2. Jakarta: Erlangga, 1993.

Lindo Systems, Inc., Lindo User Manual. Chicago: Lindo Systems, Inc., 2003

Wigbout, F. Buku Pedoman Tentang Bekisting (Otak Cetak). Diterjemahkan oleh: Hendarsin H. Jakarta: Penerbit Erlangga. 1992. 